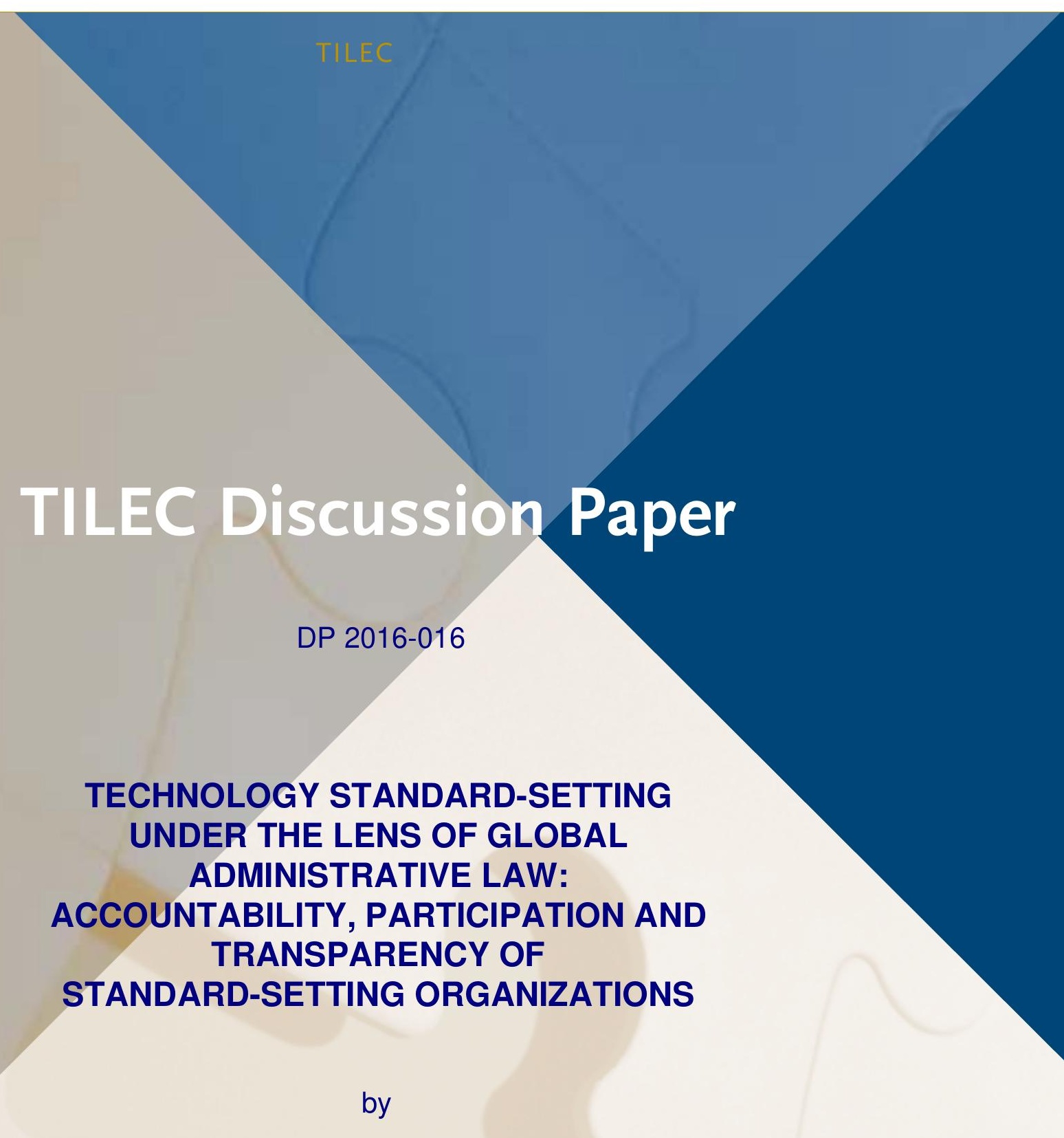

Olia Kanevskaia

July 21,2016

ISSN 1572-4042 


\title{
Technology Standard-Setting under the Lens of Global Administrative Law: Accountability, Participation and Transparency of Standard-Setting Organizations
}

\author{
Olia Kanevskaia ${ }^{1}$
}

\begin{abstract}
The role of transnational non-governmental bodies in international standardization has often been in the limelight of recent academic discussions. While standards developed by Standard-Setting Organizations (SSOs) are typically non-binding, they can nevertheless acquire an obligatory character, either by virtue of the force given to them by domestic regulation or another organization such as the WTO or by obtaining significant market power. Such metamorphosed standards, especially when developed in hybrid or private fora, are frequently accused of lacking legitimacy and accountability. In particular, these concerns are relevant for the technology sector, characterized by expertise-driven decision-making and the symbiosis of public and private stakeholders.
\end{abstract}

This paper sheds light on the mechanics of technical standard-setting by analyzing the working procedures of the public, hybrid and private SSOs leading in telecommunications and ICT standardization, namely the International Telecommunications Union (ITU), the European Telecommunications Standards Institute (ETSI) and the Institute of Electrical and Electronics Engineers (IEEE). It further suggests that despite the fundamental difference in the institutional nature of their forums, standards formulated by all three organizations constitute a collective action and fall within the scope of global administrative law. Ultimately, this paper attempts to reveal the principles, which could serve as administrative tools for scrutinizing the indirect powers of the SSOs, and to provide a preliminary comparative assessment of the examined procedures with regard to the identified principles.

Keywords: International Standard-Setting, Private Voluntary Standards, Global Administrative Law, Transparency and Participation in Global Administration

JEL Classification: D82, F13, F14, F23, F53, K23, K33, L15, L32,

\footnotetext{
${ }^{1}$ Contact: o.s.kanevskaia@uvt.nl. Tilburg Law and Economics Centre (TILEC), Tilburg University, the Netherlands. The author wishes to thank the participants of the 2nd Lisbon International Workshop on Global Administrative Law, "Global Administrative Law(S): Unity and Diversity of Global Administrative Regimes", the 5th Annual Conference of Cambridge Journal of International and Comparative Law, "Public and Private Power" and Timothy Wyndham for their comments on the earlier versions of this paper, and Panos Delimatsis for his feedback and guidance. All errors are author's own.
} 


\section{Introduction: Voluntary SSOs as Catalysts of International Technology Standards}

The eon of continuous scientific development and flourishing transnational trade generated the demand for coordination of emerged technologies. In particular, the need to ensure proper functioning and compatibility of electronic devices gave raise to the explosive growth of technical standards, which define complex mechanical and technological features. Typically described as sets of specifications that provide a common design for products or processes, ${ }^{2}$ technical standards do not only ensure the quality of numerous technology elements and services, but also provide for their interoperability, enabling 'communication' between various devices. ${ }^{3}$ Yet, due to their normative character and large network effects, ${ }^{4}$ standards might significantly affect competition among technology manufacturers by preventing those who do not comply with certain technical requirements from entering the market: ${ }^{5}$ in this case, the use of standards is likely to result in a trade barrier or even impede technological advancement.

Given their composite normative structure, ${ }^{6}$ it does not come as a surprise that technical standards have traditionally been a matter of private expertise at national level. ${ }^{7}$ It is for the reasons of the rapid economic growth and the necessity of global technical harmonization, that standards recently acquired international dimension and at the same time whetted the appetite of governments to take part into standards development. The latter phenomenon can be explained by the fact that, once serving

\footnotetext{
${ }^{2}$ Lemley, 'Intellectual Property Rights and Standard-Setting Organizations', 90 California Law Review (2002) 1889, at 9.

${ }^{3}$ Spulber, 'Innovation Economics: The Interplay Among Technology Standards, Competitive Conduct, and Economic Performance', 9 Journal of Competition Law and Economics (2013) 777.

${ }^{4}$ See Delimatsis, 'Into the Abyss of Standard-Setting: an Analysis of Procedural and Substantive Guarantees within ISO', TILEC Discussion Paper 0042-2014, available online at https://www.tilburguniversity.edu/research/institutes-and-researchgroups/tilec/research/publications/discussion-papers/, at 2 ( last visited 4 June 2016), and Lane, 'The Social Regulation of Inter-firm Relations in Britain and Germany: Market Rules, Legal Norms and Technical Standards', 21 Cambridge Journal of Economics(1997) 197.

${ }^{5}$ Geradin, 'The European Commission Policy towards the Licensing of Standard-Essential Patents: Where Do We Stand?', 9 JCLE (2013) 1125, at 1126.

${ }^{6}$ See Pauwelyn, Wessel and Wouters, 'The Exercise of Public Authority Through Informal International Rule Making: an Accountability Issue?' Jean Monnet Working Paper 06/ 2011, available online at http://jeanmonnetprogram.org/wp-content/uploads/2014/12/JMWP06Wessel.pdf (last visited 4 June 2016).

${ }^{7}$ Büthe and Mattli, 'Setting International Standards: Technological Rationality or Primacy of Power?' 56 World Politics (2003) 1, at 4.
} 
as the gap-fillers for inefficient or even impossible States' regulation, ${ }^{8}$ private technology norms expand their latitude to public organs, re-shaping the conventional governance system. To this extent, technical standards often embody the outcomes of an extensive collaboration between private and public stakeholders. The formulation and endorsement of technical specifications typically occur in so-called StandardSetting Organizations (SSOs), ${ }^{9}$ which serve as a forum for cooperation and coordination between interested actors. ${ }^{10}$

This paper seeks to shed light on the descriptive aspects of industry-driven standardization by defining actors and processes of the leading technology SSOs, namely the International Telecommunications Union (ITU), the European Telecommunications Standards Institute (ETSI) and the Institute of Electrical and Electronics Engineers' Standards Association (IEEE-SA). To that end, it analyses the legal frameworks of these three organizations with regard to their membership, voting rights and decision-making. Based on those findings, the paper applies the notion of global administrative law to the institutions at issue, tackling the binding force of voluntary standards resulting from their significant market power. Ultimately, it provides the preliminary normative assessment of standard-setting procedures regarding the principles of accountability, transparency and participation.

The selection of the SSOs for the descriptive part of this paper is motivated by several factors: firstly, the three institutions at issue proved to be the prominent suppliers of technology and ICT technical specifications, ${ }^{11}$ and hence they play a significant role in the field of technical innovation. Secondly, given the popularity of these SSOs, their activities are presumed to attract a great variety of stakeholders, which in turn have their own reasons to join the standardization fora. Ultimately, all three organizations enjoy a certain level of authority in the field of telecommunications and ICT.

\footnotetext{
${ }^{8}$ S. Cassese, 'Administrative Law without the State? The Challenge of Global Regulation' 37 N.Y.U. International Law and Politics (2004-2005) 663, at p. 671.

${ }^{9}$ Büthe and Mattli, supra note 7, at 2 -3.

${ }^{10}$ See the definition suggested in Curran, 'Standard-Setting Organizations: Patents, Price Fixing, and Per Se Legality', 70 The University of Chicago Law Review (2003) 983.

${ }^{11}$ As it will be discussed infra, all three SSOs served as platforms for the development of the most famed standards in the field.
} 
2. Defining the Actors of Technology Standardization: the ITU, ETSI and IEEESA

\section{A. Voluntary SSOs and Binding Standards}

Since the institutional character of the SSOs prevents them from mandating binding decisions, standards generated by those bodies are generally voluntary and cannot impose any particular obligations: the opposite scenario would contradict the principle of democratic rule-making, as it would imply that binding norms can be generated by private and in most cases, unspecified actors. The exceptions would be when such standards are implemented into domestic legal systems, ${ }^{12}$ and their application is a prerequisite for compliance with (inter) national law. ${ }^{13}$ Likewise, standards can be denoted mandatory by another organization, what is illustrated by the requirement of WTO law to use existent relevant international standards as a basis for its Members' technical regulations. ${ }^{14}$ Under both conditions, initially voluntary standards are deemed de jure binding, and the process of their conversion is accompanied by another legal tool, such as domestic or international legislation.

Yet, standards formulated in hybrid or private organizations may as well acquire de facto binding force: this is the case when other regulatory alternatives are not available, or when the functioning of the market is conditional upon the use of a particular set of requirements. ${ }^{15}$ In the latter situation, the binding force of a rule is reliant on the willingness of the relevant market to follow it. In the recent past, such transformation of a non-binding standard into a mandatory norm was acknowledged by the European Court of Justice (ECJ), which stated that a technical standard drafted

\footnotetext{
${ }^{12}$ A reference to a standard in national legislation transforms a voluntary standard de jure binding; see S. Cassese, Global Administrative Law. Cases and Materials (2006) available online at http://www.iilj.org/gal/documents/galcasebook.pdf (last visited 6 July 2016), at 23, and Murphy and Yates, 'Coordinating International Standards: The Formation of the ISO' (2006), available online at http://web.mit.edu/iandeseminar/Papers/Fall2006/Yates.pdf (last visited 5 July 2016) at 26.

${ }^{13}$ For instance, under the New Approach, Member States' authorities are obliged to recognize that products manufactured in accordance with harmonized European standards comply with essential requirements. Conformity with harmonized European standards gives a right of free movement. See Joerges, Schepel and Vos, The Law's Problems with Involvement of Non-Governmental Actors in Europe's Legislative Processes: the Case of Standardization under the New Approach', EUI Working Paper No. 99/9, available online at http://cadmus.eui.eu/bitstream/handle/1814/154/law99_9.pdf?sequence=1, at 12 -14 (last visited 5 July 2016).

${ }^{14}$ Article 2.4 TBT Agreement.

${ }^{15}$ See H. Schepel, The Constitution of Private Governance: Product Standards in the Regulation of Integrating Markets (2005).
} 
by a private organization could factually determine companies' presence on a country's market. ${ }^{16}$

An example of a voluntary standard subject to compliance pull is the famous set of the IEEE standards for the Wi-Fi chipsets, which enabled interconnection of electronic technologies via wireless telecommunications. In that case, the industrywide commitment to the standard was a consequence of the growing number of wireless devices and large network effects of wireless connections. ${ }^{17} \mathrm{~A}$ similar recognition can be attributed to the H.264 (or MPEG-4 AVC) standard developed by the ITU-T in collaboration with the ISO and IEC and applied universally for video recording and distribution, ${ }^{18}$ or the broadly used GSM specifications issued by the ETSI. ${ }^{19}$ The industry-wide acceptance of the mentioned standards can perhaps be explained by their function of providing interoperability between devices: evidently, compatibility of technological platforms can play a vital role in achieving a critical mass of producers of technical components and users of the technology and by this expand the size of the market. ${ }^{20}$ By the same token, the adoption of a single standard by few large firms is likely to incite its approval by other market-players. ${ }^{21}$

The aforementioned examples reveal the regulatory metamorphosis of voluntary standards developed within private or hybrid settings. It comes as no surprise that such practice raises a number of substantial legitimacy and accountability concerns, demanding effective instruments that would define and control the powers of standard setters. Due to the ambiguities the latter, the definition of such mechanisms should commence with the description of stakeholders of technical standardization.

\section{B. 'Public' and 'Private' Actors}

\footnotetext{
${ }^{16}$ Case C-171/11 Fra.bo SpA v Deutsche Vereinigung des Gas- und Wasserfaches [2012].

${ }^{17}$ See the case study performed by Delacey et al., 'Strategic Behavior in Standard-Setting Organizations' (2006) available online at https://www.researchgate.net/publication/228138342 Strategic Behavior in StandardSetting_Organizations (last visited 6 July 2016), at 3.

${ }^{18}$ ITU-T Recommendations: Advanced video coding for generic audiovisual services http://www.itu.int/ITU-T/recommendations/rec.aspx?rec=11466\&lang=en (last visited 1 November 2015).

${ }^{19}$ See Gandal, Salant and Waverman, 'Standards in Wireless Telephone Networks' (2003) available at http://www.tau.ac.il/ gandal/telecomstandards.pdf (last visited 4 June 2016); however the development of this set of standards was preceded by an EU Directive introducing conditions for the development of the future European Mobile Telecommunications System.

${ }^{20}$ This is illustrated by an example of the cellar phone users; Rogers, 'Diffusion of Innovations: Modifications of a Model for Telecommunications', The Free Press New York (1995), at 245.

${ }^{21}$ See Jakobsen, 'Revisiting Standard-Setting Organizations' Patent Policies', 3 Northwestern Journal of Technology and Intellectual Property (2004) 43, at 59.
} 
In an ideal situation, technical and technology standards represent scientific decisions and aim to provide the most effective response to the technological needs of the international community. ${ }^{22}$ Following this reasoning, the establishment of such standards should be free from any political considerations, ${ }^{23}$ and is therefore entrusted to the industry representatives, which possess sufficient technical knowledge. However, notwithstanding this expertise-driven character, the growing demand for the regulation of technology- and telecommunication-related services, together with the sensitivity of such services in terms of human rights and security, prevents standards issued in that domain from entirely escaping governmental purview: as a result, standard-setting processes often feature cooperation and coordination between public and private actors.

Although States typically prefer industry representatives to fill in the regulatory gaps associated with specialized knowledge and skills, ${ }^{24}$ their occasional presence in standardization activities has a number of explanations. ${ }^{25}$ The engagement of governments in standard-setting processes might not only balance divergent interests of various stakeholders, but also provide for more public control, which is lacking in the regulatory framework of industry - dominated SSOs. ${ }^{26}$ Moreover, given their function as the 'guardians of citizens' rights', ${ }^{27}$ participation of public actors might add a certain authoritative power and credibility to the process of standards development. Finally, it is worth mentioning that actors of a purely private voluntary organization might be tempted to ignore institutional tenets, which would eventually cause the collapse of institutional agreements: ${ }^{28}$ allegedly, such situation is likely to be prevented by inclusion of the public sector into standard-setting fora and letting them exercise the role of 'watchdogs'.

As opposed to the actors pursuing States' interests, the motives of private entities to join standardization projects are most likely of commercial nature. By being

\footnotetext{
${ }^{22}$ Majone, 'The Internationalization of Regulation: Implications for Developing Countries' in M. Minogue and L. Cariño (eds.), Regulatory Governance in Developing Countries (2006) 39, at 42.

${ }^{23}$ Büthe and Mattli, supra note 7, at 13.

${ }^{24}$ Cassese, supra note 8.

${ }^{25}$ I.e. safety at work regulation, environmental policy objectives, see Joerges, Schepel and Vos, supra note 13 , at 41 .

${ }^{26}$ Ibid., at 9 .

${ }^{27}$ Bonnici and Cannataci, 'Can Self-Regulation Satisfy the Transnational Requisite of Successful Internet Regulation?' 17 International Review of Law Computers \& Technology (2003) 51, at 54.

${ }^{28}$ Lenox, 'The Role of Private Decentralized Institutions in Sustaining Industry Self-Regulation', 17 Organization Science (2006) 677 , at 677.
} 
associated with the creation of technical norms and specifications, companies prove their operational efficiency and communicate their technical superiority. ${ }^{29}$ Furthermore, since technical standards often embed patented elements, technology owners are spurred by the possibility to promote their inventions for the inclusion in technical specifications. ${ }^{30}$ Last but not least, involvement in technical standard-setting expands companies' knowledge and frequently offers first-mover advantage on the relevant market. ${ }^{31}$

It appears that technical and, in particular, technology standardization attracts both governmental ('public') and non-governmental ('private') stakeholders. In this regard, it is assumed that the essential difference between the 'public' and 'private' notions, as used for the purposes of this analysis, lies in stakeholders' motivation to join standards development processes. Whereas public stakeholders are presumed to be governmental agencies acting under the authority of a State and not pursuing any commercial interests, private stakeholders comprise of parties that do not engage in the process of standard-setting on behalf of a State: their actions are guided by scientific, commercial or individual considerations. ${ }^{32}$ Yet, bearing in mind the potential regulatory and social importance of standards and specifications defined by those stakeholders, it is crucial to reveal the powers of standardization actors and the necessary mechanisms for their control. The principal reason for such examination is the fact that, in the absence of sufficient public scrutiny, de facto binding norms generated in private settings undermine the very idea of democratic rule-making, for norm-setters do not represent norm-receivers. ${ }^{33}$ This paper suggests that the tools to safeguard the interests of those affected by technology standards are to be found in the domain of global administrative law.

Despite the evident reference to public administration, global administrative law can be developed by private or hybrid institutions exercising regulatory functions, or even

\footnotetext{
${ }^{29}$ Ibid., at 678-679.

${ }^{30}$ Since those patents are essential for the functioning of a standard, technology users would have to obtain the license in order to have access to the standard.

${ }^{31}$ See Büthe, 'Engineering Uncontestedness? The Origins and Institutional Development of the International Electrotechnical Commission (IEC)', 12 Business and Politics (2010) 1, at 15.

${ }^{32}$ These concepts of public and private actors are based on the model introduced in A. Peters et al., (eds.) Non State Actors as Standard Setters (2009), at 538.

${ }^{33}$ This is in contrast to governmental fora, where norm-setters are elected or are represented via parliamentary democracy.
} 
by private bodies delivering self-regulatory schemes. ${ }^{34}$ While arranging for mechanisms to ensure the balance of power among actors within not-for-profit organizations ${ }^{35}$ and prevent excès de pouvoir, ${ }^{36}$ global administrative law also addresses the interdependence of evolving fields in transnational dimension. ${ }^{37}$ Therefore, a global regulatory process in a form of committee-based standard-setting in multi-stakeholders platforms, such as the ITU, ETSI and IEEE, ${ }^{38}$ should be scrutinized in the light of the principles of global administrative law, revealing its actors and their role in the relevant processes.

In this regard, the difference in the institutional architecture of the three selected SSOs plays a crucial role in the further discussion, allowing for a comparative analysis of procedural and substantive aspects of their standardization processes. For instance, whereas the governmentally driven ITU is expected to offer enhanced procedural guarantees due to its formal character and experience, ${ }^{39}$ its inflexibility might thwart the formulation of the most effective technological solution due to the limited involvement of industry. ${ }^{40}$ In turn, the semi-public governance of the ETSI and the private setting of the IEEE are presumably characterized by weaker rulemaking ${ }^{41}$ and democratic deficit of their potentially binding decisions. Since the involvement in all three organizations is not mandatory, the collective behavior of the players is controlled by their voluntary self-association. ${ }^{42}$ In that view, the performance of an SSO is contingent on the collaboration of its members, their characteristics and the degree of involvement in the creation of standards.

\section{Membership of the SSOS}

\footnotetext{
${ }^{34}$ Kingsbury, Krish and Steward, 'The Emergence of Global Administrative Law', 68 Law and Contemporary Problems (2005) 15, at 16.

${ }^{35}$ Benvenisti, 'The Interplay Between Actors as Determinant of the Evolution of Administrative Law in International Institutions', 68 Law and Contemporary Problems (2005) 319, at 325.

${ }^{36}$ Harlow, 'Global Administrative Law: The Quest for Principles and Values', 17 EJIL (2006) 187, at 192.

${ }^{37}$ Kingsbury, Krish and Steward, supra note 34.

${ }^{38}$ Oshri and Weber, 'Cooperation and Competition Standard-Setting Activities in the Digitalized Era: the Case of Wireless Information Devices', 18 Technology Analysis and Strategic Management (2006) 265 , at 267.

${ }^{39}$ Baron and Pohlmann, 'Who Cooperates in Standards Consortia - Rivals or Complementors?' 9 JCLE (2013) 905, at 906.

${ }^{40}$ See Hinricher, 'The Law Making in the International Telecommunications Union (ITU) - Providing

a New Source of International Law?' 64 Heidelberg Journal for International Law (2004) 489.

${ }^{41}$ See Böstrom and Tamm Hallström, Global Multi-Stakeholder Standard Setters: How Fragile Are

They?' 9 Journal of Global Ethics (2013) 93, available at

http://dx.doi.org/10.1080/17449626.2013.773180 (last accessed 5 July 2016).

${ }^{42}$ Lenox, supra note 28.
} 
Forasmuch as the suggested descriptive analysis is based on the regulatory frameworks of the three institutions at issue, the first step in revealing the actors of the SSOs is the examination of their membership rules. As it is the case for almost every (international) organization, members or affiliates enjoy privileged treatment compared to the 'outsiders' or observers, and often determine the scope of organization's activities by participating in its governance. ${ }^{43}$ To acquire membership, parties are typically expected to fulfill certain criteria, often related to their scale, institutional nature or operational field. The benefits of an institution's membership are typically accompanied by a set of obligations, such as recurrent financial contribution or attendance of meetings. As it will be discussed further, all mentioned requirements play an importance role in the membership allocation of the SSOs.

\section{ITU}

Given its function as a specialized agency of the United Nations (UN), the ITU maintains its status of a traditional intergovernmental institution ${ }^{44}$ and opens its voting membership exclusively to UN Member States. ${ }^{45}$ Cooperation with private parties is encouraged by allowing entities and private agencies to join in one of ITU's operational Sectors, namely the Radiocommunication Sector (ITU-R), the Standardization Sector (ITU-T) and the Development Sector (ITU-D). ${ }^{46}$ The contributions of the Sector Members are yet limited to the Sector of their affiliation, and hence to the operational activities of the ITU. ${ }^{47}$ Such governance model results in a lack of actors' representation at the organization's decision-making level, especially considering the fact that the current composition of the ITU includes 196 Member States and 800 Sector Members, the latter being predominantly global telecommunications and ICT companies from developed States. ${ }^{48}$ The legal framework of the ITU particularly welcomes participation of national, ${ }^{49}$ regional or

\footnotetext{
${ }^{43}$ By taking decisions related to financial and operational matters of an institution.

${ }^{44}$ See J. Alvarez, International Organizations as Law-Makers (2005), at 16.

${ }^{45}$ Article 2 ITU Constitution; the legal documents of the ITU are available online at http://www.itu.int/en/history/Pages/ConstitutionAndConvention.aspx (last visited 5 June 2016).

${ }^{46}$ Article 7 ITU Constitution, such model was introduced in the ITU following the 1992 Additional Plenipotentiary Conference, and was aimed to provide greater flexibility for the ITU's activities. The Sectors operate via a regular cycle of conferences and meeting.

${ }^{47}$ Article 3 ITU Constitution.

${ }^{48}$ For the list of ITU Sector Members, see https://www.itu.int/online/mm/scripts/gensel11 (last visited 11 May 2016).

${ }^{49}$ Such National entities should be endorsed by Member State's regulation. Every such national entity wishing to participate in the work of a Sector needs an authorization from the Member States of its
} 
international telecommunications agencies, scientific or industrial organizations and financial or development institutions. ${ }^{50}$ The membership dues are allocated per unit classes and depend on parties' regional and institutional background. ${ }^{51}$ Only those States listed by the UN as developing countries, or explicitly determined as such by the ITU Council, may pay the lowest membership fees. ${ }^{52}$ Sector Members are not allowed to select a unit class of contribution lower than $1 / 2$, with an exception for companies in developing countries.

\section{ETSI}

In comparison, the membership categories of the ETSI cover a wide range of entities, including administration, ${ }^{53}$ administrative bodies and National Standardization Organizations (NSOs), ${ }^{54}$ network operators and service provides, manufacturers, users $^{55}$ and, finally, research bodies. ${ }^{56}$ At the moment of writing, the ETSI counts 800 members from 66 countries: ${ }^{57}$ out of all members, manufacturers constitute the most represented group (nearly 42\%), while users and governmental bodies are in substantial minority. ${ }^{58}$ To acquire ETSI affiliation, applicants have to demonstrate their interest in the Institute's activities, concentrated around issuing telecommunications standards and specifications. The members' roles in the work of the ETSI depend on the membership grade, which varies from full and associate membership to observership. Only applicants who are located within the geographical area of the $\mathrm{CEPT}^{59}$ can acquire full membership of the ETSI, allowing those who do

approval as such organization. Regional or international telecommunications or standardization bodies and exempt from this requirement, and can directly request the Union's Sector Membership.

${ }^{50}$ Article 19 ITU Convention.

${ }^{51}$ Article 7 and Article 33 ITU Convention.

${ }^{52}$ Article 33 ITU Convention.

53 The Rules of Procedure define ‘administration' as a part of public (emphasis added) administration responsible for electronics communications, referring to the bodies not covered by administration as to the 'other governmental bodies', see Annex 1 ETSI Rules of Procedure; the ETSI legislation referred to in this paper is codified in ETSI Directives, available online at https://portal.etsi.org/Resources/ETSIDirectives.aspx (last visited 3 June 2016).

54 The NSO are the 'public' element of the hybrid ETSI-structure: States join the Institute via their national committees.

55 The term 'user' is described as an organization making use of services in the field of electronics communications and related areas, and having main interest in standards in capacity of users (emphasis added), what factually eliminates individual end-users from acquiring the Institute's membership.

${ }^{56}$ Articles 6.1 and 6.3 ETSI Statutes, Annex 1 Article 1 ETSI Rules of Procedure.

${ }^{57}$ For the current list of ETSI members, see http://www.etsi.org/membership/current-members, (last visited 11 May 2016).

${ }^{58}$ See http://www.etsi.org/images/files/ETSIGenericPresentation.pdf (last visited 11 May 2016).

${ }^{59}$ European Conference of Postal and Telecommunications Administrations, see http://www.cept.org/cept/about-ceptm for the membership list (last visited 11 May 2016). 
not fulfill that criterion to become associate members with certain voting limitations. ${ }^{60}$ Observership can be obtained by those who meet the conditions of full or associate membership but still choose not to participate fully in the proceedings of the Institute. ${ }^{61}$ Observers are neither entitled to vote in the governance-related matters, nor can they attend standards development meetings. The annual contributions for the ETSI membership are based on parties' turnover ('private') or GDP ('public'). ${ }^{62}$

\section{IEEE-SA}

As opposed to the ETSI, the distinctions of the membership grades and categories in the IEEE are based on, among others, applicant's income, status and professional competence. ${ }^{63}$ Those who do not satisfy the requirements of any categories can participate in certain activities as Society Affiliates, ${ }^{64}$ or Associate Members with a limited power to vote. ${ }^{65}$ Yet, a different situation can be sketched once we turn to the IEEE-Standards Association (IEEE-SA). Being a specialized unit ('Major Board') of the Institute ${ }^{66}$ and thus its integral part, the IEEE-SA nevertheless maintains its own regulatory framework; its membership requirements are therefore different from the ones introduced by the IEEE. Pursuant to the relevant legal documents, the IEEE-SA accepts a great variety of stakeholders, including governmental agencies at different state-organizational levels, trade associations, commercial entities and individuals. ${ }^{67}$ Although the latter do not necessarily have to be affiliated with the IEEE, a prior membership of the Institute is indirectly encouraged by lower membership fees. ${ }^{68}$ The IEEE-SA further distinguishes between individual and entity-members ${ }^{69}$, both empowered to vote in standardization processes. ${ }^{70}$ Hence, the membership range is rather broad, the only stringent admission requirement being demonstrated interest in standards activities.

\footnotetext{
${ }^{60}$ Article 6.4 and 6.5 ETSI Statutes.

${ }^{61}$ Article 1.2.4 ETSI Rule of Procedure and Article 6.6 ETSI statutes.

${ }^{62}$ Annex 2 ETSI Rules of Procedure.

${ }^{63}$ See section I-100 of IEEE Bylaws, available online at http://www.ieee.org/about/corporate/governance/index.html?WT.mc id=lp_ab_gd (last visited 5 June 2016).

${ }^{64}$ I-103 IEEE Bylaws.

${ }^{65}$ I-104 IEEE Bylaws.

${ }^{66}$ I-303 IEEE Bylaws.

${ }^{67}$ I-403 IEEE Bylaws.

6853 US \$ against 245 US \$ for external parties; see 6.2 IEEE-SA Operations Manual, the IEEE-SA governing documents are available at https://standards.ieee.org/about/sasb/index.html (last visited 4 June 2016).

${ }^{69}$ This distinction relates to the methods of standards development discussed infra.

${ }^{70}$ 6.3.1 IEEE-SA Operations Manual.
} 


\section{Preliminary Conclusion}

It follows from this preliminary analysis that the institutional frameworks of all three SSOs in principle admit both public and private actors as their members, whilst the dominance of private expertise can be derived from the current composition of the examined organizations. Such setting seems entirely compatible with the earlier suggested image of technical standardization as an industry-driven process. In this regard, the ITU represent a non-traditional International Organization, since its functioning is essentially based on cooperation between governmental and private sectors. At the same time, the intergovernmental framework of the ITU might prove to be inadequate in addressing the private concerns of the telecommunications market. Moreover, the allocation of the membership dues within the Union is likely to discourage certain stakeholder groups, for instance SMEs or non-for profit organizations from developed countries, ${ }^{71}$ from participating in its activities.

The membership criteria of the IEEE-SA and the ETSI appear more lenient than those of the ITU: for this reason, these two Institutions are presumably capable to accommodate more interests than the intergovernmental ITU. The fact that, within the ETSI, observers have to fulfill the same conditions as full or associate members but are subject to lower membership fees, indicates that actors may self-determine their degree of participation in the activities by opting for observership rather than membership. The regional restriction of the ETSI can be explained with the rationale behind the Institute's creation, namely the addressing of the needs of European telecommunication standardization. ${ }^{72}$ From all three SSOs, the standardization sector of the IEEE demonstrates the highest level of flexibility in the admission to its membership.

Although the abovementioned findings, in part, shed light on the participants of the three major standardization fora, they do not suffice to reveal the actors behind standards development. Therefore, the crucial element of this institutional analysis is the determination of stakeholders' role in standard-setting processes, their decisionmaking powers and the degree of their contribution. While focusing on the function of

\footnotetext{
${ }^{71}$ Sector Members from developed countries are not allowed to select lower membership fees.

${ }^{72}$ See Pelkmans, 'The GSM Standard: Explaining a Success Story', 8 Journal of European Public Policy (2001) 432.
} 
various stakeholders' groups, the next section seeks to map the standard-setting procedures of the ITU, ETSI and IEEE-SA.

\section{Defining the Processes of Technology Standardization: the ITU, ETSI and IEEE}

The approach taken in this paper suggests that a committee-based standardsetting within an SSO should be divided into three stages: proposal for standardization activity, technical work on standard's design and the approval of the (draft) standard. Despite the shortcuts of this outline ${ }^{73}$ and its relative simplicity, at present, it is deemed the most practical method for the comparative assessment of standards development because all three phases are represented in the frameworks of the SSOs at issue.

\section{A. Stage One: Standardization Proposal}

\section{ITU}

Standardization activities within the ITU's Standardization Sector can be initiated either by the Member States or Sector Members. ${ }^{74}$ Accordingly, a private stakeholder can propose new project only after becoming a member of the ITU-T. A new work item proposal should be submitted to the relevant Study Group (SG) of the ITU-T: each SG is dedicated to a special industry field and provides the necessary setting for the developing of technical specifications. ${ }^{75}$ What appears rather striking is that neither the ITU's regulatory framework, nor its website provides information with regard to the procedure that should be followed for the preparation and submission of standardization proposal.

\section{ETSI}

Being a regional SSO, the ETSI endues its members, the European Commission and the EFTA with the right to initiate a standardization activity. ${ }^{76} \mathrm{~A}$ new item proposal should be supported by at least four full and/or associate ETSI members, which are

\footnotetext{
${ }^{73}$ As we will see further, some stages consist of more phases.

${ }^{74} \mathrm{See}$ http://www.itu.int/en/ITU-T/about/Pages/development.aspx (last visited 11 May 2016).

${ }^{75}$ Ibid.

76 'How does ETSI make standards' http://www.etsi.org/standards/how-does-etsi-make-standards (last visited 29 October 2015).
} 
also expected to actively participate in the future standards development. Every ETSI work item is provided with a Rapporteur, who is an individual serving as a prime contact point for technical matters and work progress. ${ }^{77}$ Once prepared, the proposal is subject to approval by the relevant Technical Body, which, similar to the SG of the ITU-T, is an entity within the main organization dedicated to a special industry field. A standardization proposal is adopted if $71 \%$ of the votes in the Technical Body are in its favor, or, in case that quorum is not achieved, if the percentage of supporting votes of full members reaches $71 \%{ }^{78}$

\section{IEEE-SA}

Whereas the proposal stage of the IEEE-SA appears more comprehensive than the one of its public and hybrid counterpart, it can also be considered less rigid. In principle, the IEEE-SA allows everyone, regardless of their affiliation, to bring forward standardization proposals, provided that those are technically and financially achievable, fall within the purpose of the IEEE activities and benefit society. ${ }^{79}$ The relevant actors, as well as their willingness to take an active part in the project, should be determined prior to its launching ${ }^{80}$ in order to jointly draft a Project Authorization Request (PAR). This highly detailed legal document states the reason and intentions behind the proposed standardization project. Parties working on the PAR act under the supervision of a Sponsor, an organization that controls the technical content of the prospect project. ${ }^{81}$ Once drafted, the PAR is submitted by the Sponsor to the New Standards Committee (NesCom), which verifies whether the proposed project falls within the scope and the purpose of the $\operatorname{IEEE}^{82}$, whether it is assigned to a proper

\footnotetext{
${ }^{77}$ Article 1.6.2. ETSI Technical Working Procedures.

78 'Approval Processes' http://www.etsi.org/standards/how-does-etsi-make-standards/approvalprocesses (last visited 5 June 2016).

${ }^{79}$ The Standards Development Lifecycle, 'Who can Participate?' https://standards.ieee.org/develop/participate.html (last visited 11 May 2016).

${ }^{80}$ Although the Working Groups are formed after the proposal is approved, parties can already start working in so-called Study Groups, which form the potential basis of the future Working Groups. See the Standards Development Lifecycle http://standards.ieee.org/develop/index.html (last visited 11 May 2016).

${ }^{81}$ Article 5.2.2 IEEE-SA Standards Board Bylaws and Article 5.1 IEEE-SA Standards Board Operations Manual; traditionally, the Sponsors for IEEE standards are IEEE Societies and Committees, Standards Coordinating Committees (SCCs), the Corporate Advisory Group or Standards Board. The IEEE-SA Corporate Advisory Group may only act as a Sponsor for entity-based Study/Working Groups together with another IEEE Sponsor or when another Sponsor cannot immediately be determined; see IEEE-SA Study Group Guidelines. For the current list of Sponsors, see https://development.standards.ieee.org/pub/view-sponsor-pnps (last accessed 3 November 2015). ${ }^{82}$ I.e. scientific development, advancing of theory and practice of electronic engineering, worldwide enhancing of the quality of life, see Article I IEEE Bylaws.
} 
Sponsor and if all interested parties are appropriately represented in the processes. ${ }^{83}$ The process of defining and formulating a standard starts directly after the formal approval of the PAR by the IEEE-SA Standards Board comprised of IEEE and IEEESA members. ${ }^{84}$

\section{B. Stage Two: Technical Work}

\section{ITU}

Upon acceptance by the ITU-T SG, standardization proposals are transferred into Study Question and subsequently assigned to the relevant Working Group (WG). The SGs and WGs include experts representing the Members, who are typically individuals nominated by governments, international organizations and private companies. ${ }^{85}$ A team of experts working on a Study Question is referred to as 'rapporteurs group'. Documentation available from the ITU website reveals that the rapporteurs groups consist of large industry representatives, national telecommunications authorities and standardization bodies. ${ }^{86}$ Several rapporteur groups ${ }^{87}$ are dominated by industry-representatives, while other groups ${ }^{88}$ are predominantly comprised of national agencies and authorities. Importantly, it is possible for a party to be represented in a WG by more than one rapporteur. ${ }^{89}$

\section{ETSI}

Unlike the legal instruments of the ITU, the ETSI Directives impose a requirement for the members to be represented by solely one expert. ${ }^{90}$ Technical work on standards formulation is conducted within the special Committees of the Technical Organization, the Technical Bodies. ${ }^{91}$ Where a decision has to be taken, parties are obliged to endeavor consensus, which yet does not imply unanimity. If consensus

\footnotetext{
${ }^{83}$ See 4.2.2 IEEE-SA Standards Board Bylaws; the work of the NesCom is complemented by the reviews of the Standards Review Committee (RevCom) and the Audit Committee (AudCom). The first mentioned verifies if the consensus in the balloting group has been achieved, the last one provides the oversight of relevant procedures.

${ }^{84}$ Article 4.1 IEEE-SA Standards Board Bylaws.

${ }^{85}$ See the Annex of the ITU Convention.

${ }^{86}$ See the rapporteurs group members at http://www.itu.int/en/ITU-T/studygroups/20132016/Pages/default.aspx (last visited 7 April 2016).

${ }^{87}$ for instance those of SG 11 on Protocols and Tests and of SG 15 on Transport and Access.

${ }^{88}$ Ex. SG Economic and Policy.

${ }^{89}$ Ex. Huawei and Orange in SG 5 on Environment and Climate.

${ }^{90}$ Article 1.4 ETSI Technical Working Procedures.

${ }^{91}$ Those can be ETSI Projects, Technical Committees, ETSI Partnership Projects, and their Working Groups, Article 15 ETSI Rules of Procedure.
} 
cannot be achieved, a (possibly secret) voting takes place. ${ }^{92}$ In certain situations, the ETSI might open a call for expertise to support the work of the Technical Organization..$^{93}$

\section{IEEE-SA}

The formulation of standards and technical specifications within the IEEE-SA takes place in its WGs. The composition of those groups is determined only after the approval of the PAR, and often includes actors involved in the first stage. Consequently, each Working Group is tailor-made for a specific standard activity. The WGs are accessible to all individuals and corporations with the relevant technical expertise, knowledge and dedicated interest in the relevant project. ${ }^{94}$ Yet, those wishing to take part in the committee voting are subject to additional organization fees. ${ }^{95}$ An important distinction is made between the individual and the entity methods of standard-setting: the major difference between the two lies in the fact that under the entity method, experts are nominated by the company of their affiliation, which in turn has to be a member of the Standards Association. ${ }^{96}$ This requirement does not apply to persons joining the individual-based committees. The WGs strive to achieve broad and balanced representation of all parties interested in standardization projects, and encourage global engagement by, i.e. approaching the members of the IEEE for their interest and expertise and issuing a call for participation. ${ }^{97}$ Similar to the ETSI, the IEEE-SA obliges participating experts to be representatives of the organization of their affiliation..$^{98}$

\section{Stage Three: Approval of Standard's Drafts}

\section{ITU}

Standards or technical specifications developed within the ITU-T take the form of voluntary ITU Recommendations. Their approval typically occurs in the fast-

\footnotetext{
${ }^{92}$ Article 1.7.1 ETSI Technical Working Procedure.

${ }^{93}$ See, for instance, call for proposal for Specialist Task Forces, https://portal.etsi.org/stf/OpenCallForExperts (last visited 4 June 2016).

${ }^{94}$ See 'The Standards Development Life Cycle' http://standards.ieee.org/develop/index.html (last visited 11 May 2016).

${ }^{95}$ Article 5.2.1.3.1 IEEE-SA Standards Board Bylaws.

${ }^{96}$ See the website IEEE.

${ }^{97}$ See The Standards Development Lifecycle, http://standards.ieee.org/develop/index.html (last visited 11 May 2016).

98 5.4.4.1 IEEE-SA Standards Board Operations Manual.
} 
track 'Alternative Approval Process' (AAP), unless the Recommendations fall within the ITU-T standardization domain of numbering/addressing or tariff/charging/accounting: in that case, the traditional approval procedure (TAP) applies. ${ }^{99}$ After the draft Recommendation is considered mature and consent of the relevant SG is obtained, it opens for online comments from all ITU members, aiming to provide equal opportunities to both States and Sector Members to participate in the 4-week approval procedure. ${ }^{100}$ The Recommendation is approved in case no substantial comments have been received. Otherwise, the comments are sent back to the experts for further consideration, followed by an Additional Review Process. ${ }^{101}$

\section{ETSI}

In turn, standards' approval processes within the ETSI vary according to the type of the deliverable and the scope of its application. Whereas the endorsement of all ETSI standards requires the consensus of the relevant Technical Committee/Body and the successful balloting of all members of the Institution, ${ }^{102}$ the approval procedure of the European Standard (EN) is distinct due to the EN's regulatory impact. After approval of the relevant Technical Body, the draft standard opens for Public Enquiry by the NSOs (National Standards Organizations). In the following 120 days, the NSOs undertake national consultations and deliver their comments and national positions. Another part of the process is the weighted national voting, wherein the votes are allocated per States according to Annex 3 of ETSI's Rules of Procedure. ${ }^{103}$ The NSOs can vote in favor or against the adoption of the draft, providing reasons for their negative votes, or abstain.

The crucial role of the ETSI standards implementation is left for the NSOs, which are charged with the transposition of EN to the domestic (legal) system. ${ }^{104}$ Likewise, the NSOs are obliged to take measures for ensuring the visibility of EN application at national level: this occurs either by a publication of a text identical to the standard or

\footnotetext{
${ }^{99}$ WTSA-08 - Resolution 1vSec. 8. The TAP is categorized by the formal consultation process with Member States prior to the draft's approval on the SG's meeting.

100 To do so for the period of 2013-2016, an individual affiliated with an ITU members should fill in and submit the form at http://www.itu.int/en/ITU-T/info/Pages/aap-contact.aspx (last visited 4 June 2016).

101 'Standards Approval' http://www.itu.int/en/ITU-T/about/Pages/approval.aspx (last visited 29 October 2015).

${ }^{102}$ Article 14 ETSI Rules of Procedure.

${ }^{103}$ Article 11.2 ETSI Rules of Procedure; the largest amount of votes (29) is allocated to Germany, France, United Kingdom and Italy.

${ }^{104}$ Article 13 ETSI Rules of Procedure.
} 
an endorsement sheet, or by an announcement. ${ }^{105}$ Importantly, all ETSI members are prohibited from undertaking any national standardization activities, which could prejudice preparation of an EN, including publishing or revising standards incompatible with an existing EN. ${ }^{106}$ Such commitment is referred to as a 'Standstill obligation', and does not have an equivalent within the ITU and the IEEE standardization processes.

\section{IEEE-SA}

Much as the first stage, the approval procedure within the IEEE-SA is more cumbersome than the one of the ITU and the ETSI, and therefore requires a detailed explanation. Upon reaching consensus at the second stage of standardization and announcing by the Sponsor that the draft standard is sufficiently mature, the project is moved to the phase of the Sponsor balloting. At that point, the Sponsor forms an individual or entity-based balloting group, ${ }^{107}$ whose composition is not always equal to the one of the relevant WG. In order to be eligible for voting, members of the balloting group should be affiliated with the IEEE-SA or pay a per-ballot fee. ${ }^{108}$ Each group member has one vote, and can give his or her comments when approving or disapproving a draft, or abstain from voting at all. Every negative vote should be supported by specific reasons. ${ }^{109}$ Importantly, no company or individual may dominate the process, and no interest category can comprise over one-third of the balloting group. ${ }^{110}$ In order for a draft standard to pass this phase, the balloting should result in consensus, meaning that $75 \%$ of the group has to vote, $75 \%$ of those votes have to be in favor, and that all technical or editorial comments submitted with the votes are responded to. ${ }^{111}$

Together with the initiation of a consensus ballot, a draft standard opens for the 60days IEEE-SA Public Review Process, providing an opportunity for any interested party to comment on the draft that is being reviewed in the consensus process and to

\footnotetext{
105 Article 13.7 ETSI Rules of Procedure.

${ }^{106}$ Article 13.3 ETSI Rules of Procedure.

${ }^{107}$ See 5.4 IEEE-SA Standards Board Operations Manual.

${ }^{108}$ One can become a member of a balloting group by joining the online IEEE-SA myProject tool and applying for a balloting processes of a specific project.

109 5.4.3.2 IEEE-SA Standards Board Operations Manual.

110 5.4.1 IEEE-SA Standards Board Operations Manual.

111 5.4.3.3 and 5.4.3.5 IEEE-SA Standards Board Operations Manual.
} 
obtain responses from the WG. ${ }^{112}$ Any person can purchase a ballot draft and submit comments via the IEEE website. ${ }^{113}$ After the draft has undergone the Public Review Process and achieved consensus in Sponsor balloting, it moves to the IEEE-SA Standards Board for its final approval. ${ }^{114}$ The Standards Board reviews the document and its supporting material and takes its (dis)approval decision based on a recommendation of the RevCom, which examines whether the relevant procedural principles were respected throughout the development procedures. ${ }^{115}$ Once approved, the final draft standard is edited and eventually published as an IEEE standard. Its adoption by national, regional and international SSOs is strongly encouraged in the IEEE legislation, and occurs through a formal process, possibly including a reciprocal agreement between the IEEE and the implementing organization. ${ }^{116}$

\section{Comparison: Private vs. Governmental Actors}

Despite the evident similarities between the procedures of the ITU, ETSI and IEEE-SA, the performed descriptive study also unveils asymmetries in the actors' engagement in standard-setting processes. The first crucial distinction relates to the range of stakeholders' participation, which generally varies among the three standardsetting stages and might be explained by the differences between their function. Since the proposal stage typically requires an appreciable amount of technical and financial research, but also lobbying for the project's support, the industry-driven character of this phase may be diluted by the overshadowing presence of governmental actors, whose authoritative power is likely to add considerable weight to a standardization proposal. In turn, the second stage is characterized by extremely technical decisions taken by experts during the WG's meetings, and is presumed to be dominated by the private sector, although governmental representatives might sometimes form the majority of the technical group. ${ }^{117}$ Even if the industry or governmental experts might

\footnotetext{
112 5.4.5 IEEE-SA Standards Board Operations Manual.

113 The IEEE- SA project are available for public enquiry at http://publicreview.standards.ieee.org/public-review-web/public-app (last visited 5 June 2016); an IEEE account is required in order to post comments.

${ }^{114}$ Article 45.2.4 IEEE-SA Standards Board Bylaws.

115 Those principles include consensus, due process, openness, and balance, see http://standards.ieee.org/develop/finalapp.html (last visited 29 October 2015), and Article 4.2.3 IEEESA Standards Board Operations Manual. ${ }^{116}$ Article 5.6 Standards Association Operations Manual.

117 See the example of the SG in ITU, supra note 88.
} 
not necessarily be the direct standardization stakeholders, ${ }^{118}$ their contributions in essence represent the affiliates of the SSOs. Finally, the last stage seems to involve the greatest amount of stakeholders and in principle aims at enquiry and control by those potentially affected by the standard.

The second distinction lies within the difference in participation in the three SSOs. Unlike the IEEE, the norm-setting of the ITU and the ETSI do not provide space for individual members to act following their private or scientific considerations. Moreover, the ITU significantly lacks any enforcement or policing mechanisms, ${ }^{119}$ as opposed to the ETSI, which maintains a strong Standstill commitment during the development of the ENs. ${ }^{120}$ This obligation can perhaps be explained by the ETSI's leading role in harmonization of regional telecommunication standards, and emphasizes the importance of standards' implementation at the national level. In contrast, the IEEE considers the implementation of its deliverables by other organizations as a rather contractual matter.

Whereas the ETSI and the IEEE-SA strive to ensure procedural equality within their WGs, a balanced stakeholder representation is not endorsed as such within the ITU. At the same time, the IEEE-SA might be denoted 'unfair' for its requirement to purchase the voting rights for the balloting procedures, which somehow limits its flexibility. Yet, the standards approval processes of the IEEE-SA allow everyone, subject to prior approval, ${ }^{121}$ to join the online enquiry: this approach presumably allows all interested parties to review and comment on the standard. As opposed to the IEEE, the ITU and ETSI conduct the public enquiry via the State's representatives, which in turn are composed of other organizations, each having their own interests and strategies. ${ }^{122}$

It appears that the SSOs' regulatory frameworks to a large extent support the view of sociological institutionalists and realists, who see standardization as a coordination exercise combining and coordinating different technical models, approaches and

\footnotetext{
${ }^{118}$ In certain cases, the interests of experts and stakeholders are represented by different bodies, Böstrom and Tamm Hallström, supra note 41, at 20.

119 Hinricher, supra note 40, 494.

${ }^{120}$ Since Standstill is an obligation for the ETSI members, its violation might be seen as a breach of members' obligations, which might have severe consequences for the membership, see Article 8 ETSI Statutes.

121 Which can be given in a form of an e-mail confirming participation.

${ }^{122}$ Many NSOs also have commercial enterprises and other private stakeholders as their members and representatives.
} 
regulations. ${ }^{123}$ Bearing in mind the diversity of stakeholders, the technical complexity of standard-setting and the resulting challenges in decision-making, it can be assumed that standards development can only be successful if stakeholders behave collectively and purposively. ${ }^{124}$ The next section elaborates on this assumption, and ties technology standardization to the notion of global administrative law.

\section{Applicability of Global Administrative Law to Technology Standards}

According to the existing scholarship on transnational rule-making, ${ }^{125}$ one of the main peculiarities of global administrative law is an independent, committeebased decision-making, guided by scientific considerations. To a large extent, the discussed procedures of technology standard-setting fall within the scope of this definition, since the vital technology-related decisions are taken by experts (scientific) during the WGs' meetings (committee-based). ${ }^{126}$ Yet, one might argue that, albeit its industry-driven character, standardization exemplifies a political process, accompanied by economic and business considerations, ${ }^{127}$ which questions the element of 'independence'. Although the requirement of an impartial and objective expertise is considered one of the institutional features of international organizations generating effective outcomes, ${ }^{128}$ its conspicuous absence in the framework of all three SSOs can be explained by the experts' role as stakeholders' representatives. This, however, does not take away the fact that standardization, even when highly technical, occurs at the crossroads of different disciplines.

\footnotetext{
${ }^{123}$ Büthe and Mattli, supra note 7, at 9.

${ }^{124}$ In the opposite case, the discrepancy of stakeholders' approaches might result in a lengthy process of taking a decision satisfying all parties involved: the jeopardy of such process is that the standards, when finally adopted, might be less effective or even will not accepted on the market. In addition, due to the variety of stakeholders, standard-setting clearly exemplifies international co-operation which in its, essence is based on based on collective and purposive behavior of norm-shapers. In this regard, see O’Neill, Balsiger and Vandeveer, 'Actors, Norms, and Impact: Recent International Cooperation Theory and the Influence of the Agent-Structure Debate', 7 Annual Review Political Science (2004) 149, at 154 .

125 i.e. Büthe and Cassese.

126 Those are the decisions on i.e. technology incorporation, standards' design, the content of technical specifications, which typically occur at stage 2 (technical work on standards).

127 i.e. Büthe and Mattli, Schepel.

${ }^{128}$ See Meidinger, 'Administrative Law of Global Private-Public Regulation: the Case of Forestry', 17 EJIL (2006) 47, at 79.
} 
Another remarkable feature of global administrative law is a narrow line between public and private actors, ${ }^{129}$ demonstrated by the membership of the examined SSO. Whereas the regulatory frameworks of all three SSOs allow both governments and industry to take an active part in their standardization activities, certain differences within the institutions can be observed: for instance, the ITU is the only SSO which evidently distinguishes between Member States and Sector Members. ${ }^{130}$ Such separation is less apparent in the ETSI and in the IEEE: despite the private setting of the latter, its legal framework does not prohibit as such the involvement of governmental parties, ${ }^{131}$ neither does it provide for their different treatment in case of their engagement in Institute's activities.

As suggested in the previous section, standard-setting should be regarded as an exercise in coordination, ${ }^{132}$ implying the unavoidable cooperation between the public and the private sector. The rationale behind this assumption lies in the self-evident expectation of contributing parties to make certain investments as a precondition for their participation, ${ }^{133}$ on one hand, and the jeopardy of their input to be hampered by strategic interactions of other players, ${ }^{134}$ on the other, as in the latter case, parties in disadvantage are likely to leave the negotiations within the SSO in order to search for private agreement with other parties ${ }^{135}$ or join another standardization forum. Therefore, the outcome of standard-setting should be beneficial for all actors involved, because in the opposite case, they will lose the incentive to collaborate and a standard will not be set. Such reasoning points toward classification of standardsetting as a collective action, for the syndication of sources, competences and expertise in multi -stakeholder transnational SSOs leads to a common collective agreement in the form of technical standards. Moreover, the relatively stable composition of the SSOs at issue, together with the precise specification of their

\footnotetext{
${ }^{129}$ S. Cassese, supra note 8 , at 669.

130 see section 2 .

${ }^{131}$ In contrast, the International Electrotechnical Commission (IEC) prohibits any governmental interference in its standards-developing; Büthe, supra note 31, at 30.

132 Büthe and Mattli, supra note 7 , at 9.

${ }^{133}$ I.e. various transaction and information costs, including the membership dues, burdensome membership application procedures, $\mathrm{R} \& \mathrm{D}$, expertise and travelling costs.

${ }^{134}$ T. Sandler, Global Collective Action (2010), at 17.

${ }^{135}$ Delacey et al., supra note 17 , at 3.
} 
member's rights and dues, allow for the decisions taken within these SSOs, including standards' adoption, to be considered as collective actions. ${ }^{136}$

It follows from the above that, once involved in the activities of the SSOs at issue, actors will cooperate with the purpose to create commonly applicable technical norms, disregarding their conflicting interests and divergent incentives to participate in technology standardization. However, in order for that norm to be de facto binding, its effectiveness and the purposive cooperation of parties defining the norm is not sufficient; the crucial component is its wide acceptance, meaning that external actors who did not participate in the norm-setting should nevertheless comply with it. The binding power of decisions adopted by non-governmental bodies is intrinsically a matter of concern from a traditional legal viewpoint, as the classic international lawapproach asserts the capability of the instrumentum to adopt mandatory rules as the decisive element of binding power. ${ }^{137}$ In other words, organizations can generate binding norms only if they are empowered to do so by their institutional settings or by an explicit delegation. Yet, this approach does not take into account the increased phenomenon of self-regulation as a consequence of complex society, and the weakness of the State's apparatus in regulating newly emerged fields. Besides, unlike public international law, Global Administrative Law is designed to protect people against the abuse of administrative power ${ }^{138}$ and would lose its meaning if its scope merely covers norms set by governmental actors.

The unavoidable need for transnational communications in modern society further makes the functioning of the wireless telecommunications industry conditional upon the existence of universal coordinating norms. ${ }^{139}$ Consequently, the absence of selfregulation in that field might provoke an increased and possibly less effective governmental rule- making without the necessary input from industry. ${ }^{140}$ This threat can be suggested as a background factor for the widespread recognition of private voluntary standards as gap-fillers in regulatory systems. Moreover, the scope of

\footnotetext{
${ }^{136}$ Dixit, 'Governance, Institutions and Economic Activities', 99 The American Economic Review, (2009) 5, at 16.

${ }^{137}$ H. Thirlway, The Sources of International Law (2014), at 168, 169.

${ }^{138}$ Harlow, supra note 36.

139 Take, for instance, the 3G/4G, Wi-Fi, Bluetooth, USB or GSM: while those abbreviations became a self-evident part of our quotidian life, they in fact refer to the technical specifications, which enable coordinated communication; Larouche and Van Overwalle, 'Interoperability Standards, Patents and Competition Policy', in P. Delimatsis (ed..) The Law, Economics and Politics of International Standardization (2015) 367.

${ }^{140}$ Meidinger, supra note 128 , at 59.
} 
application of technology standards is enlarged by their normative function, which increases the network effects of standardization and provides for more incentives for cooperation. ${ }^{141}$

Ultimately, mandatory regulation in its essence implies a possibility to impose penalties in reaction to a norm violation, in this way forcing the parties in breach to comply with the rules. ${ }^{142}$ Such option is not provided by the legal framework of the SSOs at issue due to their non-obligatory nature: in principle, it would be absurd for an organization based on voluntary membership to penalize external stakeholders for non-adherence to its decisions. However, compliance with a private voluntary standard would become a condition for market-entry once the standard is accepted on that market, in fact putting players who did not implement it in a disadvantageous position, or even excluding them. ${ }^{143}$ In this regard, those who do not comply with the standard can be considered as the 'wrongdoers' when they attempt to operate in the market dominated by that particular standard, and their eventual exclusion by the market-mechanism exemplifies indirect sanctioning, thereby transforming a voluntary norm into a de facto binding regulation.

This section argued that the development of technology standards within the SSOs at issue takes form of a collective action carried out in an extensive collaboration between public and private stakeholders, and is capable of resulting in de facto binding norms, compliance with which determines parties' presence and position on the market. Given the importance of technology standards in the contemporary world and the necessity to monitor their development processes, it is clear that standardsetting cannot be addressed by traditional rule-making mechanisms. Yet, completely unregulated standardization, wherein the powers of actors are not determined and their actions are not constrained, is likely to give rise to a number of fundamental concerns, including the legitimacy and accountability of the SSOs' technical decisions. These concerns can be successfully tackled by global administrative law, which is applicable to technology standard-setting.

\footnotetext{
${ }^{141}$ Delimatsis, supra note 4, at 2.

${ }^{142}$ See, for instance, Hadfield and Weingast, 'Law without the State: Legal Attributes and the Coordination of Decentralized Collective Punishment', 1 Journal of Law and Courts (2013) 3.

${ }^{143}$ Büthe, supra note 31 , at 2,3.
} 


\section{The Relevant Principles of Global Administrative Law and their Application to the Technology Standard-Setting}

Having its roots in national administration, global administrative law champions the rights of individuals to be protected against undesired and/or unnecessary transnational regulatory powers, and introduces a number of principles to be followed for a legitimate and accountable rule-making, including openness, participation, transparency and due process. Remarkably, a number of these principles are reflected in a TBT Committee Decision on international standards. ${ }^{144}$ Following the WTO acquis, standards crafted according to those principles are presumed not to constitute a trade barrier. ${ }^{145}$ In contrast to international law, where legal principles typically underline or explain the rules and the rationale behind them, ${ }^{146}$ their role in global administrative law is leading due to the nonexistence of any binding rules in that field, and accordingly, they bear considerable weight in the scrutiny of standards development procedures.

\section{A. Legitimacy}

Despite its frequent mentioning in the relevant literature, the notion of legitimacy still preserves certain obscurity. While its normative aspect relates to compliance with explicitly defined rules, the sociological legitimacy allegedly depends on the acknowledgment and acceptance of decisions issued by organizations, ${ }^{147}$ partially resembling the concept of binding force discussed above. In this regard, a legitimate decision-making institution should be capable of generating effective norms and policies by the means of providing opportunities for discussions and evaluation of various views and interests, promoting diversity and reducing the risk of opportunistic interventions. ${ }^{148}$

\footnotetext{
${ }^{144}$ WTO, TBT Committee Decision on Principles for the Development of International Standards, Guides and Recommendations with relation to Articles 2,5 and Annex 3 of the Agreement, Annex 4 of the Second Triennial Review of the Operation and Implementations of the Agreement on Technical Barriers to Trade, 2000, G/TBT/9.

${ }^{145}$ See Article 2.5 and Annex 3 TBT Agreement.

146 Thirlway, supra note 137 , at 95.

147 Keohane, 'The Contingent Legitimacy of Multilateralism', GARNET Working Paper: No 09/06, 2006, available at http://www2.warwick.ac.uk/fac/soc/pais/research/researchcentres/csgr/garnet/workingpapers/0906.pdf (last visited 3 June 2016), at 2.

$148 \mathrm{Ibid}$, at 15 .
} 
Such setting is partly reflected in the IEEE-SA, which, at least in theory, allows everybody to participate in the process and comment on the draft standards, but assigns decision-making only to those willing to put extra effort (payment) and are seemingly parties with the largest expertise and interest in the project. As indicated in section 4, participation in the ETSI and ITU is guaranteed by their Member States, which must ensure that the views of all interested stakeholders are represented at the appropriate stages of standards development. In both organizations, decision-making is limited to their members, in principle preventing any substantive interventions from non-members.

Yet, notwithstanding its indisputable importance for standard-setting, the legitimacy of an SSO's decision does not necessarily imply the existence of effective procedural tools within its institutional framework: to establish the latter, the examination of fundamental procedural principles is in order. For this reason, further legitimacy analysis falls outside the scope of this paper and will be subject to a separate and more extensive research. Instead, the focus of this paper will shift to the notion of accountability, and the related principles of participation and transparency.

\section{B. Accountability}

Being a relatively elusive concept, accountability is considered to provide both traditional and non-conventional regulatory institutions with the outside scrutiny grip. In this regard, it aims to moderate the substantial democratic deficit of their rulemaking through allowing the observations by public society, ${ }^{149}$ focusing on such institutional proxies as transparency, participation and review. ${ }^{150}$ The most evident case of accountable decision-making would thus be a regulatory delegation that is possible to trace back to domestic law. Yet, it is suggested that in transgovernmental networks, accountability can be achieved through involving parties affected by decisions in the processes of the organizations adopting them. ${ }^{151}$ In the case of wireless telecommunications and the ICT industry, this would imply an active participation of, i.e. producers of wireless devices and representatives of downstream markets, but also consumers.

\footnotetext{
${ }^{149}$ See i.e. Stasavage, 'Open-Door or Closed-Door? Transparency in Domestic and International Bargaining', 58 International Organization (2004) 667.

${ }^{150}$ Meidinger, supra note 128 , at 81 .

${ }^{151}$ This can be deduced from Grant and Keohane, supra nota 138.
} 
There are two important questions that arise when it comes to the accountability of a transnational organization: for what should the institution be accountable, and who should be empowered to hold it accountable? ${ }^{152}$ Whereas the answer to the first question can be formulated around the power of the organization to issue widelyapplicable norms, an SSO is primarily accountable to those who are directly and indirectly affected by the generated standard, including its members, but also multiple stakeholders which are not affiliated with the particular standardization forum. ${ }^{153}$ In this regard, accountability does not only require greater openness of the SSOs, but also emphasizes the significance of consultation with all stakeholders, whose interests might be at stake. Accordingly, groups working on technical standardization should not only address the needs of the market and industry, but also communicate with national administrations and civil society. ${ }^{154}$

Again, it appears that the IEEE-SA scores the highest on this point by setting rather lenient requirements for commenting on draft standards and allowing the input from individuals. Yet, the fact that the ETSI and ITU make their standards publicly available significantly contributes to the transparency of those SSOs by opening their technical documents to the general public. Hence, it appears that the accountability of an institution cannot be considered apart from the principles of participation and transparency. While the latter evidently intertwines with the concept of accountability, the function of both principles is to restrain the powers of stronger parties, preventing them from imposing their will during negotiations. ${ }^{155}$ Likewise, accountability can be achieved by greater participation and increased stakeholders' engagement in the bargaining processes, offering possibilities to intervene in the course of norm-setting.

\section{Participation}

Simply providing opportunities for participation would not suffice in the context of global rule-making: following the foundations of the democratic

\footnotetext{
${ }^{152}$ See Peters, Föster and Koechlin, 'Towards Non-State Actors as Effective, Legitimate and Accountable Standard Setters', in A. Peters, et al. (eds.), Non State Actors as Standard Setters, (2009) 492.

${ }^{153}$ Gulbrandsen, 'Accountability Arrangements in Non-State Standards Organizations: Instrumental Design and Imitation', 15 Organization (2008) 563, available online at http://org.sagepub.com/cgi/content/abstract/15/4/563 (last visited 6 July 2016), at 578.

${ }^{154}$ Cassese, supra note 8 , at 681 .

${ }^{155}$ Benvenisti, supra note 35 , at 326.
} 
governance model, a SSO should also encourage and promote meaningful and effective involvement. ${ }^{156}$ This implies the ability of stakeholders to attend the meetings at all three standardization stages, contribute to standards development and take an active part in the decision-making processes. ${ }^{157}$ For instance, technical specifications and standards development policies, which are biased against particular interests, signify lack of participation within an SSO ${ }^{158}$ Participation should not result in an institutional protest: rather, it seeks to represent "effective policy shaping based on early consultations and past experience". 159

To this extent, the IEEE-SA seems to be the least rigid in the admission to its standardization activities, and presumably engages more players than other institutions. Although 'purchasing' of the voting rights in the IEEE-SA and the ETSI apparently restricts participation, it simultaneously grants parties autonomy to decide on the extent to which they wish to be involved. ${ }^{160}$ The ITU compensates for its relatively strict conditions to obtain Sector membership by allowing members to participate in public enquiry processes, increasing, at least in theory, the scrutiny of the Union's standardization work. Remarkably, whereas the approval of the ETSI Standards (ES) only requires $71 \%$ votes of the members to be in favor of adoption, the ENs, which commonly serve as a basis for European harmonized standards, require the consent of all NSOs. This difference can perhaps be explained by the reluctance of the States to loose their grip on technical norms related to regulatory aspects. 161

Furthermore, the IEEE-SA deviates from the other two organizations in the composition of working groups, charged with standardization activities. For instance, a sponsor balloting group of stage 3 can involve actors different than those participating in a working group of stage 2, which in turn is formed only after approval of the PAR. Consequently, although the opposite is more likely to occur in practice, the PAR drafting group can be different than the group working on the

\footnotetext{
${ }^{156}$ Moravczik, 'Is There a 'Democratic Deficit' in World Politics? A Framework for Analysis' (2004), available online at https://www.princeton.edu/ amoravcs/library/framework.pdf (last visited 6 July 2016), at 7.

157 Delimatsis, supra note 4, at 19.

${ }^{158}$ In this regard, see Moravczik, supra note 156, at 22.

${ }^{159}$ Harlow, supra note 36, at 202.

${ }^{160}$ Considering the rather moderated prices of balloting membership and the requirement to be affiliated with the relevant fields of work as the only statutory limitation to acquire it.

${ }^{161}$ See Annex A.3 of ETSI Technical Working Procedures for the definition of ETSI deliverables.
} 
technical content of a standard. In addition, given that for their successful adoption, standards and technical specifications require an approval at three different levels, ${ }^{162}$ the IEEE-SA standardization is presumed to be subject to more scrutiny than the one of the ITU or ETSI. ${ }^{163}$

Whereas one might argue that an open discussion, in which all affected interests are evenly represented, is problematic within the framework of the ETSI and the ITU due to the limitations of membership rights, it is mostly their processes of public enquiry, which are likely to affect representation of interested stakeholders. Unlike the IEEESA, the ITU and ETSI conduct their public consultation via national members, those being the NSOs or Member States' agencies, which in turn consist of other, possibly multi-stakeholder, organizations. This makes the actual motives behind the SSOs' decisions rather challenging to reveal, and requires a complex assessment of all NSOs and Member States' agencies with regard to their actors and decision-making systems.

Yet, an active and effective participation also has certain drawbacks. For instance, making international bargaining more accessible might have detrimental effects, possibly leading to breakdowns in negotiations ${ }^{164}$ or a longer standard development. Increased participation and larger transparency can result in over-accountability and dissipate the effectiveness of technical processes. ${ }^{165}$ In a narrow specialized technology field, such undesired intervention would undermine the very idea of an industry regulation as an effective response to the needs of society. Consequently, there is a need for an appropriate balance between limiting the powers of standardization actors, ensuring the rights of the market players and providing public scrutiny.

Since the work of the SSOs is generally targeted at benefiting society ${ }^{166}$ and providing an efficient response to the needs of international community, ${ }^{167}$ the interplay of standardization actors should also balance the challenge of achieving consensus at transnational level with the swift designing of a technical norm. In a self-regulatory

\footnotetext{
${ }^{162}$ Namely, sponsor balloting, public enquiry and approval of the Standards Board.

${ }^{163}$ The Standards Board and related committees verify whether the relevant procedural processes were respected during standards development.

${ }^{164}$ Stasavage, supra note 149, at 668.

${ }^{165}$ Hadfield and Weingast, supra note 142, at 4.

166 Jakobsen, supra note 21, at 47.

${ }^{167}$ Majone, supra note 22.
} 
system, the processes of norm-creation would be efficient when they represent impartial, accurate and consistent decisions, which in turn foster the effectiveness of an administrative system ${ }^{168}$ and hence result in collective benefits. Allegedly, an effective norm is more likely to be defined by a homogenous rather than heterogeneous group of stakeholders: whereas the first mentioned is typically perceived as strong in its views and positions, a heterogeneous group embodies players with highly divergent interests, which affects the speed of their decisionmaking. ${ }^{169}$

\section{Transparency}

The challenges of accountability can furthermore be addressed by greater transparency. ${ }^{170}$ In terms of public scrutiny, transparency would imply, inter alia, the availability of an organization's regulatory outcomes, the visibility of its decisions and access to the resources that motivate the regulatory outcomes and decisions. ${ }^{171}$ Increased transparency is likewise essential for the functioning of an SSO in a multistakeholder context, ${ }^{172}$ as the lack of transparency generally results in information asymmetry within the group of interested actors, and might provide them with incentives to switch to another forum. ${ }^{173}$ Consequently, an SSO should endorse transparency toward both external and internal stakeholders.

In the case of the ITU, ETSI and IEEE-SA, the existence of public enquiry, together with the availability of institutions' bylaws and standard-setting procedures, ${ }^{174}$ speaks in favor of transparent decision-making. Remarkably, the standard-setting procedures as introduced in the legal basis of the ITU are less comprehensive than the ones put forward in the IEEE-SA's Bylaws and ETSI's Directives, while the complexity of the technical processes is presumably equal in all three institutions. ${ }^{175}$ Again, the position of the IEEE-SA is quite exceptional due to the accessibility of the minutes from the WGs' meetings. The ITU limits the publicly available information to the names and

\footnotetext{
168 O’Neill, Balsiger and Vandeveer, supra note 124.

${ }^{169}$ Böstrom and Tamm Hallström, supra note 41, at 19, 20.

${ }^{170}$ See i.e. Krisch and Kingsbury, 'Introduction: Global Governance and Global Administrative Law in the International Legal Order', 17 EJIL (2006) 1.

${ }^{171}$ See Fisher, 'Transparency and Administrative Law: A Critical Evolution', 63 Current Legal

Problems (2010) 272.

172 Böstrom and Tamm Hallström, supra note 41, at 15.

${ }^{173}$ A. Dixit, Lawlessness and Economics: Alternative Modes of Governance (2004), at 65.

174 Those can be downloaded for free from SSOs' websites.

175 This is apparent from the fact that all three generate complex and comparable technology standards.
} 
affiliations of the members of its rapporteur groups. Such is not the case for the ETSI, which neither provides the meetings' documentation, nor the composition of the groups charged with technical activities. Moreover, while the ETSI allows its observer members to attend the meetings of the highest hierarchical body, the General Assembly, ${ }^{176}$ it yet deprives them from any sort of participation in the work of a Technical Body. ${ }^{177}$ Accordingly, the minutes of the discussions are only available to those directly involved in the meetings.

Next to the access to information, it can be assumed that the level of organization's transparency can be measured by the access to its final outcomes, meaning the approved standards or technical specifications. In this regard, the ITU and the ETSI offer an open and unrestricted access to their deliverables. ${ }^{178}$ The IEEE-SA specifications can be purchased online against a variable fee. ${ }^{179}$ Members of the IEEE-SA are entitled to a price-reduction.

\section{Conclusion}

This paper aims to address the concerns of private voluntary standards becoming de facto binding, by bringing the standard-setting procedures of the relevant SSOs under the purview of global administrative law. In this respect, it asserts that global administrative law is categorized by the amalgam of public and private players, purposively acting together with the intention of defining and adopting a norm, which would be most effective for all participants. It further submits that, despite the need of both public and private parties to be represented during standard-setting processes, the best technical solution is likely to be reached by homogeneous groups, requiring a subtle balance between those two components. This reasoning applies in particular to the area of technology and telecommunications, distinguished by expertise-driven decision-making, increased network effects and inducements for governmental and private actors to participate in technology standard setting.

\footnotetext{
${ }^{176}$ Article 1.2.4 ETSI Rules of Procedure.

${ }^{177}$ Article 1.4 ETSI Technical Working Procedures.

178 They can be downloaded via http://www.etsi.org/standards-search\#Pre-defined Collections (ETSI) and http://www.itu.int/en/ITU-T/publications/Pages/recs.aspx (ITU) (both links last visited 5 June 2016).

179 The price varies between $\$ 40$ and $\$ 800$, see http://www.techstreet.com/iee/ (last visited 4 June 2016).
} 
Taking as an example three different SSOs operating in the field of wireless telecommunications, this paper examines their legal framework regarding the actors and their contributions to standardizations processes. It suggests that the publiclydriven ITU does not per se provide for more accountability than the private IEEE-SA or the hybrid ETSI. The IEEE-SA, in turn, can be characterized by lessened participation requirements and wide range of members. The flexibility in its procedural rules confirms the IEEE's role as a platform for cooperation, wherein stakeholders are free to negotiate subject to minimum control from the Institute. ${ }^{180}$ Lastly, the ETSI represents a European SSO with rather lenient rules of participation. Unlike the ITU and the IEEE which have a wide scope of activities, ETSI is primarily concerned with defining and maintaining standards, and assigns significant weight to the implementation of standards. At the same time, both ITU and ETSI score quite high on the transparency for internal stakeholders, making its deliverables publicly available.

Although the main technical work is performed by private actors, the SSOs do not fail to include the public sector in their standardization, either via the NSO or by means of public review and consultancy with the Member States. This symbiosis between (non) governmental stakeholders, the purposiveness of the standard-setter to reach a common agreement and the market power of standards generated indicate their coverage by global administrative law.

There is a number of conclusions that can be drawn from the paper's incipient analysis. Firstly, as other forms of transnational regulation, technology standardsetting should respect the principles of accountability, participation and transparency. Yet, without the necessary balancing mechanisms, a simple compliance with those principles might jeopardize the outcome of standardization and result in overaccountability and the "triumph of populism over justice." ${ }^{181}$ Secondly, although the institutional setting of the SSOs prohibits them from issuing binding norms, standards generated by them can nevertheless become mandatory due to the market design or technical needs of society. This applies especially to technology standards, whose significance and indispensability emphasizes the need for their regulation. Lastly,

\footnotetext{
${ }^{180}$ But this does not exempt that the parties should be in compliance with Antitrust and IP policies; the same is applicable for ETSI and the ITU.

${ }^{181}$ Krisch and Kingsbury, supra note 170 , at 4.
} 
although this paper generally refers to 'public' and 'private' actors, the current composition of SSOs calls this division into question. This can be explained by the fact that SSOs' membership comprises many multi-stakeholder organizations, whose interests cannot be labeled as purely 'public' or 'private'. This brings us to the suggestion of further research, which would provide empirical support to the current descriptive findings and bring more clarity with regard to the actors and processes of technology standard-setting. 
ITU:

\begin{tabular}{c|c|c|c|} 
Member & $\begin{array}{c}\text { ITU-T Member } \\
\text { submits new work } \\
\text { item proposal to the } \\
\text { relevant Study Group } \\
\text { Member(s) propose(s) } \\
\text { new work item }\end{array}$
\end{tabular}$\longrightarrow \begin{gathered}\text { SG transfers the proposal } \\
\text { into Study Question and } \\
\text { assigns it to a Working } \\
\text { Party (WP) }\end{gathered}$

ETSI:

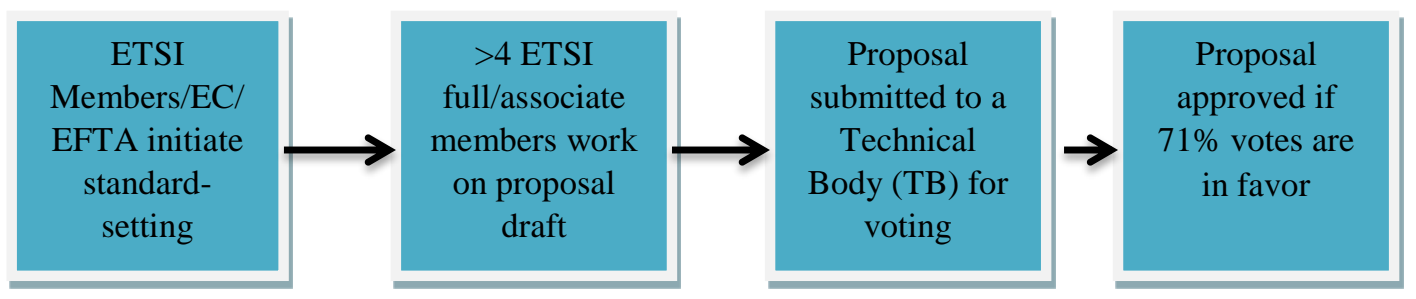

IEEE-SA:

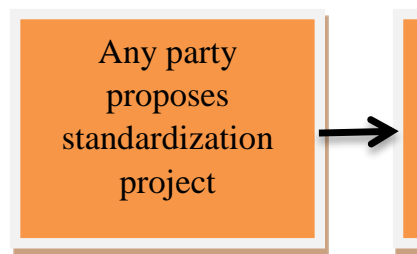

Interested stakeholders and

Sponsor draft

PAR

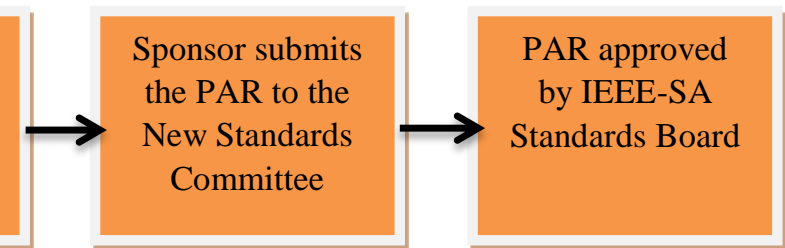


Annex II: Approval Stage

ITU:

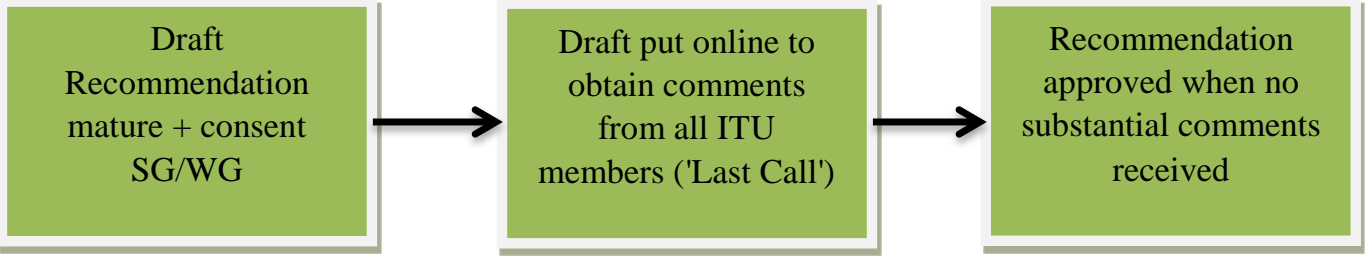

ETSI:
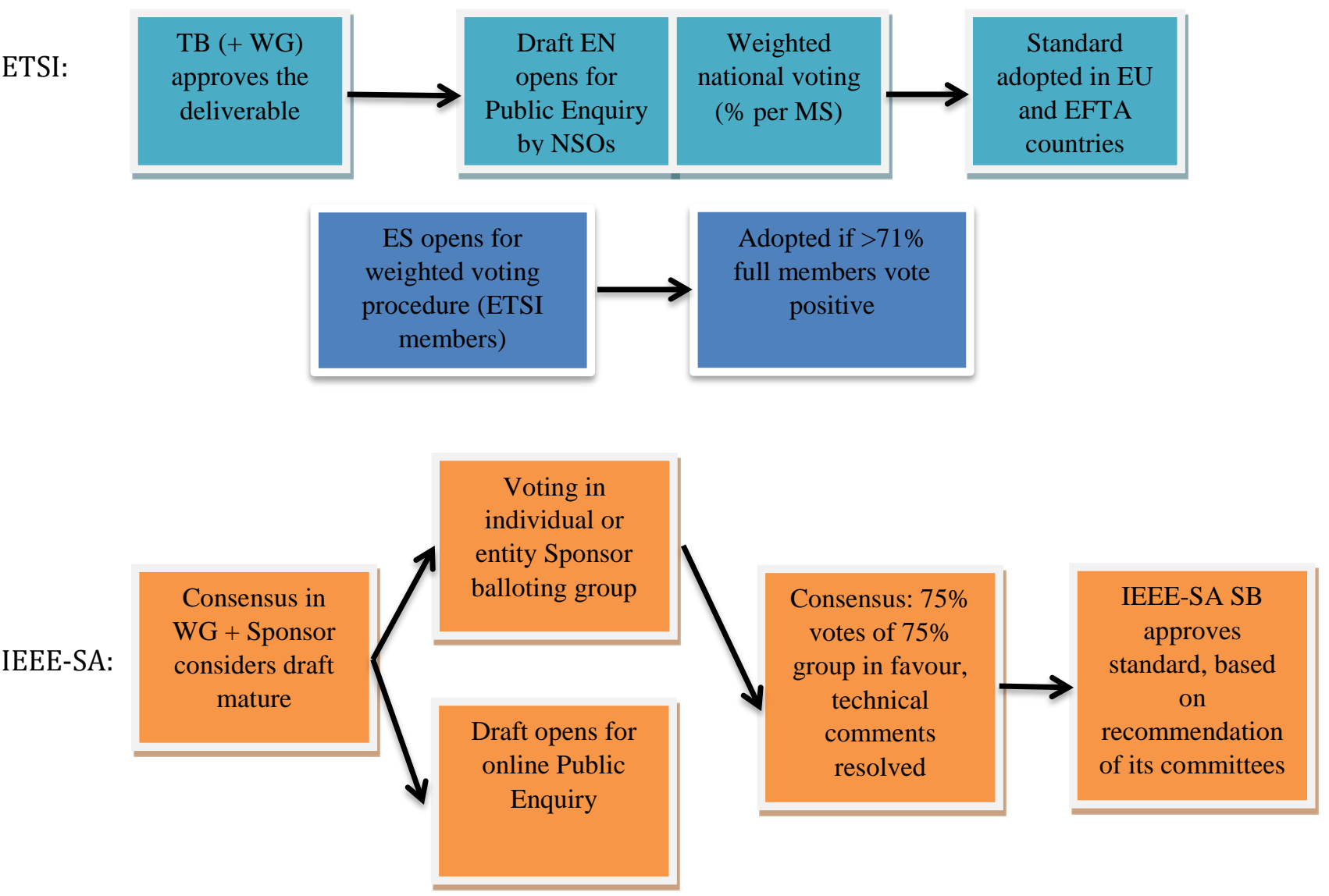